\title{
Orally exhaled nitric oxide levels are related to the degree of blood eosinophilia in atopic children with mild-intermittent asthma
}

\author{
M. Silvestri, D. Spallarossa, V. Frangova Yourukova, E. Battistini, B. Fregonese, G.A. Rossi
}

Orally exhaled nitric oxide levels are related to the degree of blood eosinophilia in atopic children with mild-intermittent asthma. M. Silvestri, D. Spallarossa, V. Frangova Yourukova, E. Battistini, B. Fregonese, G.A. Rossi. C ERS Journals Ltd 1999.

ABSTRACT: Increased levels of nitric oxide have been found in expired air of patients with asthma, and these are thought to be related to the airway inflammatory events that characterize this disorder. Since, in adults, bronchial inflammatory changes are present even in mild disease, the present study was designed to evaluate whether a significant proportion of children with mild-intermittent asthma could have increased exhaled air NO concentrations.

Twenty-two atopic children (aged $11.1 \pm 0.8 \mathrm{yrs}$ ) with mild-intermittent asthma, treated only with inhaled $\beta_{2}$-adrenoreceptor agonists on demand and 22 age-matched controls were studied.

NO concentrations in orally exhaled air, measured by chemiluminescence, were significantly higher in asthmatics, as compared to controls $(19.4 \pm 3.3$ parts per billion (ppb) and 4.0 $\pm 0.5 \mathrm{ppb}$, respectively; $\mathbf{p}<0.01$ ). Interestingly, 14 out of 22 asthmatic children had NO levels $>8.8 \mathrm{ppb}$ (i.e. $>2$ standard deviations of the mean in controls). In asthmatic patients, but not in control subjects, statistically significant correlations were found between exhaled NO levels and absolute number or percentage of blood eosinophils ( $r=0.63$ and 0.56 , respectively; $p<0.01$, each comparison). In contrast, exhaled NO levels were not correlated with forced expiratory volume in one second (FEV1) or forced expiratory flows at 25-75\% of vital capacity (FEF25-75\%) or forced vital capacity (FVC), either in control subjects, or in asthmatic patients (p>0.1, each correlation).

These results suggest that a significant proportion of children with mild-intermittent asthma may have airway inflammation, as shown by the presence of elevated levels of nitric oxide in the exhaled air. The clinical relevance of this observation remains to be established.

Eur Respir J 1999; 13: 321-326.
Divisione di Pneumologia, Istituto G. Gaslini, Genoa, Italy.

Correspondence: G.A. Rossi

Divisione di Pneumologia

Istituto G. Gaslini

Largo G. Gaslini, 5

16148 Genoa

Italy

Fax: 390103776590

Keywords: Allergy

childhood

mild-intermittent asthma

nitric oxide

Received: March 181998

Accepted after revision August 151998

Supported by Ricerca Corrente, from Ministero dell Sanità, Rome, Italy, and a grant from Valeas S.p.A. Milan, Italy (to D. Spallarossa).
Several studies have provided convincing evidence that in adults bronchial inflammatory changes are present even in mild asthma, suggesting that an ongoing recruitment and activation of inflammatory cells may be present also in asymptomatic individuals [1-3]. Mediators released by inflammatory cells have the potential to induce acute damage and the structural changes that characterize airway remodelling in asthma, leading to progressive loss of respiratory function [3-5].

These observations have led to the concept that controlling airway inflammation is an important therapeutic goal and that treatment with inhaled corticosteroids should be started as early as possible $[6,7]$. Since over two-thirds of patients with asthma have the mild form of the disease, determining the appropriate circumstances for starting antiinflammatory treatment is an issue of major importance, particularly in the paediatric population $[1,8]$.

To identify patients who need therapy and to monitor the effects of treatment, it may be important not only to record symptoms and to measure lung volumes and flows, but also to assess and gauge the intensity of airway inflammation. Techniques such as induced sputum or bronchoalveolar lavage cannot easily be performed on a routine basis even in adults $[9,10]$. In contrast, measurement of nitric oxide levels in orally expired air represents a noninvasive, simple, well-tolerated test accurately reflecting airway inflammatory events in asthmatic patients $[11,12]$.

$\mathrm{NO}$ is a mediator of vasodilation and bronchodilatation, synthesized from L-arginine by enzymes known as nitric oxide synthases (NOS), which are produced by several types of pulmonary cells, including airway epithelial, endothelial and inflammatory cells [13-15]. Several reports have demonstrated that NO levels in expired air are increased in patients with asthma $[12,16,17]$ and that exhaled NO production may reflect cytokine-mediated inflammation in the lower respiratory tract $[11,12,14,18]$.

Consistent with the observation that corticosteroids inhibit the expression of inducible NOS (iNOS) in epithelial cells [14], it has been shown that inhaled steroids are effective not only in controlling airway inflammation, but also in lowering NO levels in exhaled air [13, 19, 20].

The purpose of the present study was to evaluate whether children with mild-intermittent asthma had increased exhaled air NO concentrations, and whether NO levels correlated with simple clinical parameters, such as blood eosinophilia and pulmonary functions. 


\section{Materials and methods}

\section{Study population}

Twenty-two children (six females and 16 males, aged 5-14 yrs, mean age $11.1 \pm 0.8$ yrs) with mild-intermittent asthma and sensitized to house dust mites $(n=18)$ and/or to pollens $(n=12)$, were studied out of the pollen season. Asthma was defined according to the criteria of the American Thoracic Society $[12,17]$ and all the patients studied had a clinical history of reversible airway obstruction, characterized by a $15 \%$ increase in forced expiratory volume in one second (FEV1) after inhalation of $200 \mu \mathrm{g}$ salbuta$\mathrm{mol}$ and/or a positive inhalation challenge with methacholine. All the children were treated only with inhaled $\beta_{2}$-agonists on an as necessary basis, and therapy was discontinued at least $12 \mathrm{~h}$ before the study. Sensitization to allergens was demonstrated by skin prick tests and by titration of serum levels of allergen-specific immunoglobulin-E (IgE) by the Phadebas radioallergosorbent test (RAST) (Pharmacia Diagnostics AB, Uppsala, Sweden) [18]. As a control group, 22 sex- and age-matched children (mean age $11.9 \pm 0.7 \mathrm{yrs}$ ) were evaluated. They were nonatopic on the basis of skin prick tests negative to common inhalant allergens and normal total IgE levels in serum, nonasthmatics, and none had respiratory tract symptoms nor were treated with any drug in the two months preceding evaluation. Parents or tutors of all children were informed on the aims of the study and gave informed consent. The protocol was approved by the Ethical Committee of the Giannina Gaslini Institute.

\section{Analysis of allergic sensitization}

Allergic sensitization was determined by skin prick test, performed with a panel of 9 allergens (Dermatophagoides pteronyssinus, D. farinae, Parietaria officinalis, mixedgrass pollen, cat fur allergen extract, dog dander allergen extract, alternaria, aspergillus, and hormodendrum). A histamine solution in distilled water $\left(10 \mathrm{mg} \cdot \mathrm{mL}^{-1}\right)$ was used as positive control and the glycerol-buffer diluent of the allergen preparations as negative control. Each subject was skin tested on the volar surface of the forearm using $1 \mathrm{~mm}$ prick-lancets (Dome/Hollister-Stier, UK). The reactions were recorded within $15 \mathrm{~min}$ by evaluating the skin response rate to each allergen inoculation, in comparison with the weal given by the negative control: a weal diameter 4 $\mathrm{mm}$ larger than the negative control was considered a positive reaction.

\section{Lung function measurements}

All patients and controls were able to perform forced expiratory manoeuvres. Lung function parameters (FEV1, forced expiratory flows at $25-75 \%$ of the vital capacity (FEF25-75\%) and forced vital capacity (FVC)) were measured by spirometry (Med Graphics, Pulmonary Function System 1070 Series 2, Med Graphics Corporation, St. Paul, MN, USA). Three forced expiratory manoeuvres were performed, with the subject wearing a noseclip, and the best result was recorded and expressed as per cent of predicted values (\% pred) [21]. All patients had FEV1 values $>80 \%$ predicted.

\section{Blood eosinophil count evaluation}

Eosinophil counts in peripheral blood samples were performed by Technicon H6000 (Technicon Instrument Corporation, Tarrytown, NY, USA), a system that automatically counts and differentiates between leukocytes by an alkaline peroxidase method.

Approximately 12,000 leukocytes were counted on each occasion. The coefficient of variation $(\mathrm{CV})$ for eosinophil counts was $0.75 \%$.

\section{Detection of NO levels in orally exhaled air}

Exhaled NO was measured by a chemiluminescence analyser (Logan LR 2000 System, Rochester, Kent, UK) sensitive to NO at concentrations of 2-5,000 parts per billion (ppb; by volume), adapted for online recording of NO concentration. This feature obviates the need for collection in a reservoir, with its variable loss of reactive NO [7]. The analyser was calibrated daily using certified NO mixtures (100 ppb) in nitrogen (BOC Gases, Guildford, UK). Ambient air NO was recorded before and after each subject was studied, and was found to be always $<15 \mathrm{ppb}$. After flushing the analyser with NO-free compressed air, subjects were asked to perform a slow vital capacity manoeuvre over 15-20 s into wide-bore Teflon tubing while wearing a nose clip $[15,16,19,20]$. NO was sampled continuously at a rate of approximately $250 \mathrm{~mL} \cdot \mathrm{min}^{-1}$ with the patient blowing against a positive pressure of $6-8$ $\mathrm{cmH}_{2} \mathrm{O}$ (exhaled NO-obstructed). This manoeuvre results in increased oropharyngeal pressure, and closure of the soft palate, thereby diminishing the nasal NO component [19]. To improve test repeatability, the Logan LR 2000 System chemiluminescence analyser was equipped with an exhalation flow display, designed to provide visual guidance for the subject to maintain the exhalation flow within the desired range. The baseline NO values were measured after at least 15 min of rest. Results were displayed on a chart recorder and compared with the signal generated by a calibration mixture of NO (104 ppb) in nitrogen.

Exhaled NO was detected in all subjects: the first washout volume of expired gas, which represented the anatomical and mechanical dead space [22] and which was likely to be contaminated by nasal NO [23], generated a peak in NO values during the early part of the exhalation. This peak was followed by a plateau, associated with the last part of exhalation, which represented the NO levels derived from the lower respiratory tract $[24,25]$. Three successive reproducible recordings were made at 2-min intervals. Mean NO values of the plateau were used in all calculations and the highest value recorded (out of the three recordings) was used in NO analysis [19]. All measurements were made by two observers (D. Spallarossa and V. Frangova Yourukova), who had no knowledge of the health status of each patient. 


\section{Data and statistical analysis}

In all the patients, lung functions, blood eosinophilia and NO measurements were evaluated on the same day.

Lung function measurements were expressed as mean \pm SEM, while the number and percentage of cells were expressed as median (lower and upper quartiles). Each exhaled NO concentration was reported as mean ppb with the corresponding SEM. Comparisons between the groups were made by the Mann-Whitney U-test. Lung function parameters were compared using Student's unpaired t-test. Spearman rank $\left(r_{s}\right)$ correlation test was used to evaluate the relationship between the various parameters: $r_{(n)}$ indicates the $r$-value related to cell numbers while $r_{(\%)}$ indicates the r-value related to cell percentages. Statistical significance was assumed at a $\mathrm{p}$-value $<0.05$.

\section{Results}

Pulmonary function parameters and blood eosinophilia in asthmatic patients and controls

All subjects recruited completed the study. Mean baseline values of FEV1, FEF25-75\% and FVC of asthmatic patients and controls are summarized in table 1. As compared to controls, asthmatic subjects showed lower, but not significantly different, FEV1, FEF25-75\% and FVC values ( $p>0.05$, each comparison).

Asthmatic patients also showed a significant increase in eosinophil counts in blood samples, as compared to controls. This was true when expressing data as absolute number or as percentage of cells $(p<0.001$ and $p<0.01$, each comparison, respectively) (table 1).

\section{Exhaled NO in asthmatic patients and controls}

NO was detected in the exhaled air of each subject studied. The exhaled NO levels were significantly higher in asthmatic patients than in controls $(19.4 \pm 3.3 \mathrm{ppb}$ and $4.0 \pm 0.5 \mathrm{ppb}$, respectively; $\mathrm{p}<0.01$ ) (fig. 1). Interestingly, a significant proportion (14 out of 22) of the children with mild-intermittent asthma had NO levels $>8.8 \mathrm{ppb}$ (i.e. $>2$ standard deviations of the mean in controls).

\section{Correlations between exhaled NO levels and blood eos- inophilia or pulmonary function}

In controls, no correlations were observed between blood eosinophil counts or percentages and exhaled NO levels

Table 1. - Pulmonary function parameters and blood eosinophilia in control subjects and in asthmatic patients

\begin{tabular}{lcc}
\hline & Control subjects & Asthmatics \\
\hline FEV1 \% pred & $100.4 \pm 5.0$ & $85.5 \pm 2.3$ \\
FEF25-75\% \% pred & $107.9 \pm 5.8$ & $88.4 \pm 4.3$ \\
FVC \% pred & $96.2 \pm 4.4$ & $87.3 \pm 1.9$ \\
Eosinophils $10^{3} \cdot \mathrm{mL}^{-1}$ & $0.2(0.1-0.3)$ & $0.5(0.1-0.7)^{* * *}$ \\
Eosinophils \% & $2.8(1.8-4.8)$ & $8.4(3.7-9.8)^{* *}$ \\
\hline
\end{tabular}

FEV1: forced expiratory volume in one second; FEF25-75\%: forced expiratory flows at $25-75 \%$ of vital capacity; FVC: forced vital capacity. ${ }^{* *}: \mathrm{p}<0.01 ;{ }^{* * *}: \mathrm{p}<0.001$, as compared to control subjects.

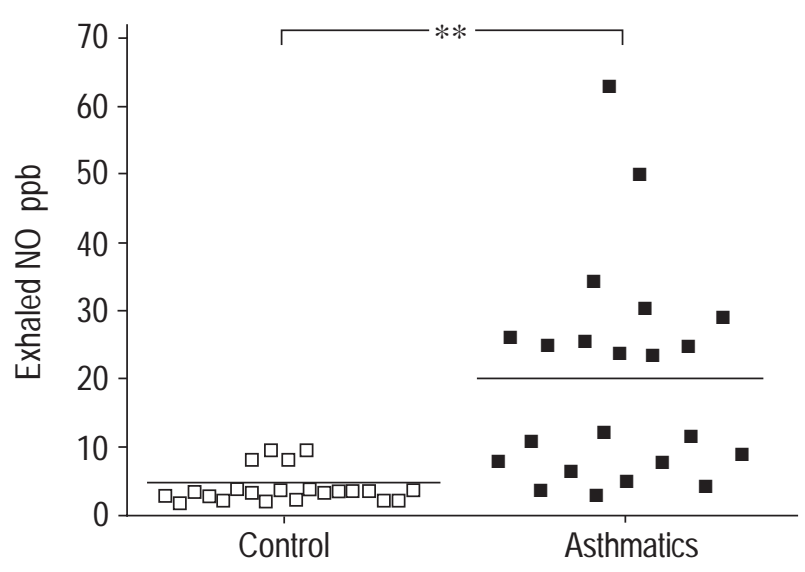

Fig. 1. - Nitric oxide levels in orally exhaled air in control subjects ( $\square$ ) and in asthmatic patients treated with inhaled $\beta_{2}$-agonists on an as necessary basis (ם). ppb: parts per billion. ${ }^{* *}$ : $\mathrm{p}<0.01$.

( $p>0.1$, each correlation). In contrast, in asthmatic patients, significant correlations were found between exhaled NO levels and the number or percentage of blood eosinophils ( $\mathrm{p}<0.01$, each correlation) (fig. 2).

No correlations were found between exhaled $\mathrm{NO}$ and FEV1, FEF25-75\%, or FVC, either in control subjects, or in asthmatic patients ( $p>0.1$, each correlation) (table 2). Finally, no correlations between blood eosinophilia and pulmonary function parameters were observed in any subject group ( $\mathrm{p}>0.1$, each correlation).

\section{Discussion}

In an evaluation of a paediatric population, NO levels were shown to be increased in a significant proportion of patients with mild-intermittent asthma and were correlated with the degree of blood eosinophilia.

In adults, there is evidence that bronchial asthma, even in its mild form, is associated with airway inflammation characterized by local infiltration and activation of eosinophils, mast cells, T-lymphocytes and macrophages [1$5,9]$. Mediators released by these inflammatory cells and by parenchymal cells (bronchial epithelial cells) have a variety of effects on airway functions, including bronchoconstriction, plasma exudation and mucus hypersecretion. Chronic inflammation may lead in some patients to irreversible structural changes, with subepithelial fibrosis and increased bulk of airway smooth muscle ("airway remodelling"). Because of these observations, various clinical practice guidelines recommend maintenance treatment with anti-inflammatory drugs for all patients with asthma, except for those with mild-intermittent disease [7, 8].

However, recent reports have provided evidence that bronchial inflammation may be present even in mild-intermittent asthma, suggesting that an ongoing recruitment and activation of inflammatory cells may be present also in asymptomatic asthmatic individuals [3, 5, 26, 27]. Although it is not known whether this "subclinical" inflammation leads to irreversible airway remodelling, it seems reasonable to evaluate the presence of airway inflammation in asymptomatic patients in order to identify individuals (children and/or adults) who may need a closer follow-up and, possibly, anti-inflammatory medications. 

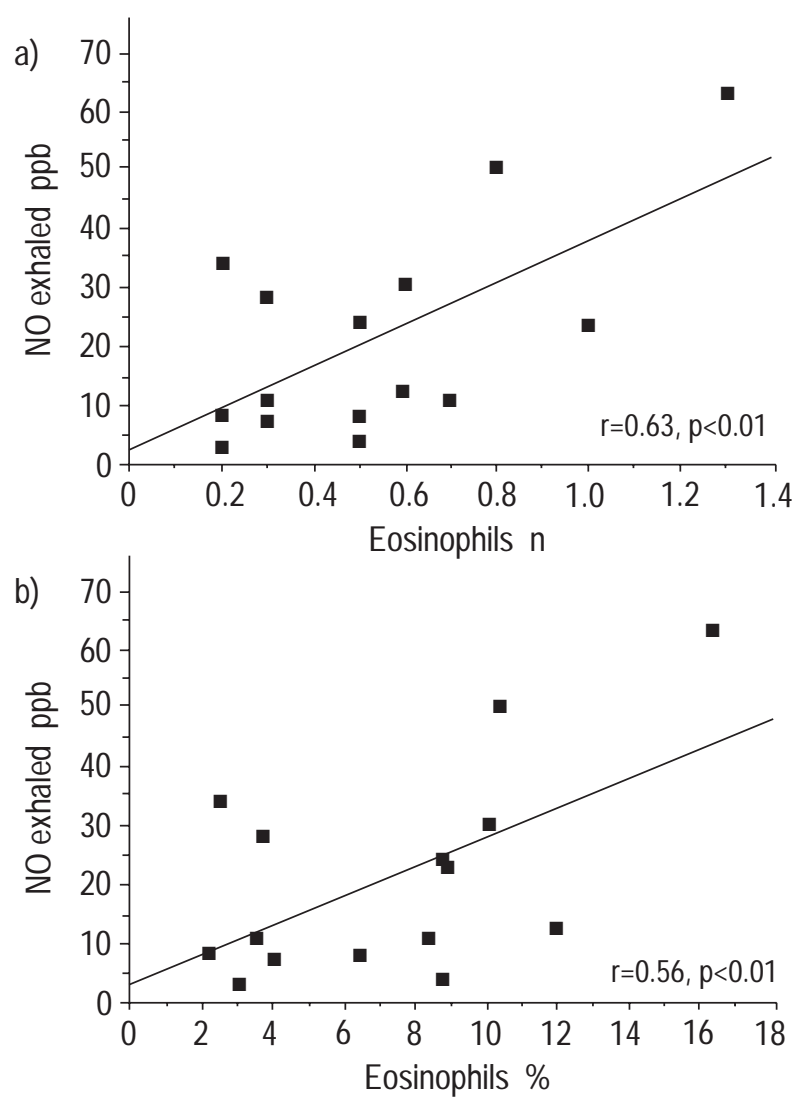

Fig. 2. - Correlations between nitric oxide levels in orally exhaled air and blood eosinophilia in asthmatic patients treated with inhaled $\beta_{2}$ agonists on an as necessary basis: a) number of eosinophils; b) percentage of eosinophils. ppb: parts per billion.

In agreement with previous observations, a significant increase in blood eosinophil counts was found in asthmatic children and positive correlations were found between blood eosinophilia and NO levels in expired air. Indeed, it has been reported that the number of eosinophils and the levels of eosinophil-derived proteins correlate with the severity of asthma [28-30], with the intensity of allergic sensitization [31], and with the degree of bronchial hyperreactivity [32-34]. Overall, these findings further support the concept that NO levels in exhaled air may indeed reflect the intensity of airway inflammation in asthma.

The relative contribution of the different cellular sources to NO levels in exhaled air is still uncertain. A variety of observations suggest that exhaled NO in asthma is likely to be derived mainly from the inducible form of nitric oxide

Table 2. - Correlations between exhaled nitric oxide and pulmonary function parameters

\begin{tabular}{llcccrcc}
\hline & & \multicolumn{2}{c}{ Control subjects } & & \multicolumn{2}{c}{ Asthmatics } \\
\cline { 3 - 4 } \cline { 6 - 7 } & & $\mathrm{r}$ & $\mathrm{p}$ & & $\mathrm{r}$ & $\mathrm{p}$ \\
\hline Exhaled NO & FEV1 & 0.19 & $<0.1$ & & -0.105 & $>0.1$ \\
& FEF25-75\% & 0.14 & $>0.1$ & & 0.041 & $>0.1$ \\
& FVC & 0.12 & $<0.1$ & & 0.069 & $>0.1$ \\
\hline
\end{tabular}

FEV1: forced expiratory volume in one second; FEF25-75\%: forced expiratory flows at $25-75 \%$ of vital capacity; FVC: forced vital capacity. synthases (iNOS or type II NOS) [13, 35-37], which are rapidly induced by pro-inflammatory cytokines in a variety of cells, including macrophages and airway epithelial cells [19]. Although we do not know the pathways linking the inflammatory events that characterize asthma with NO production in the airways, it has been demonstrated that exhaled NO levels are decreased by oral corticosteroid in patients with asthma $[20,38]$ but not in normal subjects [39].

High concentrations of NO are produced not only in the lower respiratory tract but also in the upper airways $[40,41]$. Nasally-derived NO, which may contribute to NO in exhaled air if no closure of the soft palate is achieved $[38,42]$, could give false positive results in a patient population such as that in the present study. Since the complete closure of the soft palate requires a very high degree of compliance [42], this test cannot be performed in the vast majority of children. However, a mixture of nasal and oral NO is unlikely to account for more than a minor component of exhaled NO when the patient performs a slow expiratory manoeuvre against a resistance [43, 44]. Indeed, no differences were found in exhaled NO measured either during slow exhalation against a low resistance or after isolation of the nasopharynx by inflated balloon occlusion [41]. This hypothesis is further confirmed by the observation that short course inhaled corticosteroid therapy with flunisolide, administered with metered-dose inhalers and spacers, and thus, targeted to the lower airways, was effective in downregulating exhaled air NO levels in a group of asthmatic children [45]. Similarly, it is very unlikely that in the present series, the pharmacological treatment of asthma interfered with exhaled NO levels, and patients took only inhaled $\beta_{2}$-agonists on an as-necessary basis, which were discontinued at least $12 \mathrm{~h}$ before the study NO concentrations in exhaled air are not affected by $\beta_{2}$-adrenoceptor agonists [43].

Finally, we did not find any correlations between exhaled NO levels and pulmonary function parameters. The data presented in this study are similar to those published by other groups $[44,46]$, and confirm the hypothesis that airway inflammation may not be strictly related to the reduction of lung volumes or to the degree of airflow limitation [10].

In conclusion, the present study strongly suggests that a high proportion of children with mild-intermittent asthma show evidence of airway inflammation, as judged by the increased levels of orally exhaled nitric oxide. Further studies are required to evaluate the clinical relevance of this observation.

\section{References}

1. Kay AB. Asthma and inflammation. J Allergy Clin Immunol 1991; 87: 893-907.

2. Bousquet J, Chanez P, Lacoste JY, et al. Indirect evidence of bronchial inflammatory mediators in BAL fluid of patients with asthma. J Allergy Clin Immunol 1991; 88: 649-660.

3. Oddera S, Silvestri M, Balbo A, et al. Airway eosinophilic inflammation, epithelial damage and bronchial hyper-responsiveness in patients with mild-moderate stable asthma. Allergy 1996; 51: 100-107. 
4. Olivieri D, Chetta A, Del Donno M, et al. Effects of short term treatment with low-dose inhaled fluticasone propionate on airway inflammation and remodelling in mild asthma: a placebo-controlled study. Am J Respir Crit Care Med 1997; 155: 1864-1871.

5. Bradley BL, Azzawi M, Jacobsen M, et al. Eosinophils, T-lymphocytes, mast cells, neutrophils and macrophages in bronchial biopsy specimens from atopic subjects with asthma: comparison with biopsy specimens from atopic subjects without asthma and normal control subjects and relationship to bronchial hyperresponsiveness. J Allergy Clin Immunol 1991; 88: 661-674.

6. Drazen JM, Israel E. Treating mild asthma - when are inhaled steroids indicated? N Engl J Med 1994; 331: 737739 .

7. Global Initiative for Asthma. National Institutes of Hea1th, National Heart, Lung and Blood Institutes. Bethesda, National Institutes of Health, publication No. 95-3659, January 1995.

8. The British Guidelines on asthma management 1995. Review and position statement. Thorax 1997; 52 (S1): 121.

9. Smith DL, Deshazo RD. Bronchoalveolar lavage in asthma. Am Rev Respir Dis 1993; 148: 523-532.

10. Crimi E, Spanevello A, Neri M, Ind PW, Rossi GA, Brusasco V. Dissociation between airway inflammation and airway hyperresponsiveness in allergic asthma. Am J Respir Crit Care Med 1998; 157: 4-9.

11. Barnes PJ, Liew FY. Nitric oxide and asthmatic inflammation. Immunol Today 1995; 16: 128-130.

12. Kharitonov SA, Yates D, Barnes PJ. Inhaled glucocorticoids decrease nitric oxide in exhaled air of asthmatic patients. Am J Respir Crit Care Med 1996; 153 : 454-457.

13. Kobzik L, Bredt DS, Lowenstein CJ, et al. Nitric oxide synthase in human and rat lung: immunocytochemical and histological localisation. Am J Respir Cell Mol Biol 1993; 9: 371-377.

14. Hamid Q, Springall DR, Riveros-Moreno V, et al. Induction of nitric oxide synthase in asthma. Lancet 1993; 342: 1510-1513.

15. Kharitonov SA, Wells AU, $\mathrm{O}^{\prime}$ Connor BJ, et al. Elevated levels of exhaled nitric oxide in bronchiectasis. Am J Respir Crit Care Med 1995, 151: 1889-1893.

16. Alving $\mathrm{K}$, Weitzbel $\mathrm{E}$, Lundberg JM. Increased amount of nitric oxide in exhaled air of asthmatics. Eur Respir $J$ 1993; 6: 368-370.

17. Kharitonov SA, Yates D, Robbins RA, Logan-Sinclair R, Shinebourne EA, Barnes PJ. Increased nitric oxide in exhaled air of asthmatic patients. Lancet 1994; 343: 133135.

18. Taylor DA, Lim S, Barnes PJ, O'Connor BJ. Exhaled nitric oxide production and increased airway responsiveness in asthma reflects different inflammatory pathways. Eur Respir J 1996; 9: Suppl. 23, 416S.

19. Massaro A, Gaston B, Kita D, Fanta C, Stamler JS, Drazen JM. Expired nitric oxide levels during treatment of acute asthma. Am J Respir Crit Care Med 1995; 152: 800-803.

20. Baraldi E, Azzolin NM, Zanconato S, Dario C, Zacchello F. Corticosteroids decrease exhaled nitric oxide in children with acute asthma. $J$ Pediatr 1997; 131: 381-385.

21. Veneruso G, de Benedictis FM, de Martino M, et al. Spirometric reference values for an Italian pediatric population. Riv Ital Pediatr 1987; 13: 674-681.

22. European Respiratory Society. Standardization of the measurement of transfer factor (diffusing capacity). Eur Respir J 1993; 6: Suppl. 16, 41-52.

23. Kharitonov S, Alving K, Barnes PJ. Exhaled and nasal nitric oxide measurements: recommendations. Eur Respir $J$ 1997; 10: 1683-1693.

24. Massaro AF, Metha S, Lilly CM, Kobzik L, Reilly JJ, Drazen JM. Elevated nitric oxide concentrations in isolated lower airway gas of asthmatic subjects. Am J Respir Crit Care Med 1996; 153: 1510-1514.

25. Kharitonov SA, Chung KF, Evans DJ, O'Connor BJ, Barnes PJ. Increased exhaled nitric oxide in asthma is mainly derived from the lower respiratory tract. $A m J$ Respir Crit Care Med 1996; 153: 1773-1780.

26. Kirby JG, Hargrave FE, Gleich GJ, O'Byrne PM. Bronchoalveolar lavage cell profiles of asthmatic and nonasthmatic subjects. Am Rev Respir Dis 1987; 136: 379-383.

27. Lacoste JY, Bousquet J, Chanez P, et al. Eosinophilic and neutrophilic inflammation in asthma, chronic bronchitis and chronic pulmonary disease. J Allergy Clin Immunol 1993; 92: 537-548.

28. Brusasco V, Crimi E, Gianiorio P, Lantero S, Rossi GA. Allergen-induced increase in airway responsiveness and inflammation in mild asthma. J Appl Phys 1990; 69: 2209-2214.

29. Metzger WJ, Hunninghake GW, Richerson HB. Late asthmatic responses: inquiry into mechanisms and significance. Clin Rev Allergy Immunol 1985; 3: 145-165.

30. Durham SR, Kay AB. Eosinophils, bronchial hyperreactivity and late phase asthmatic reactions. Clin Exp Allergy 1985; 15: 411-418.

31. Frangova Youroukova V, Oddera S, Silvestri M, Rossi GA. Age-dependent correlations between blood eosinophil counts and degree of allergic sensitization in children with asthma. Eur Respir J 1997; 10: Suppl. 25, 333s (Abstract)

32. Hoekstra MO, Hovenga H, Gerristsen J, Kauffman HF. Eosinophils and eosinophil-derived proteins in children with moderate asthma. Eur Respir J 1996; 9: 2231-2235.

33. Kartasamita CB, Rosmayudi O, Demedts M. Total serum $\operatorname{IgE}$ and eosinophil count in children with and without a history of asthma, wheezing, or atopy in an urban community in Indonesia. J Allergy Clin Immunol 1994; 94: 981-988.

34. Kuehr J, Frischer T, Barth R, et al. Eosinophils and eosinophil cation protein in children with and without sensitization to inhalant allergens. Eur J Pediatr 1994; 153: 739-744.

35. Moncada S, Palmer RMJ. Higgs EA. Nitric oxide physiology, pathophysiology and pharmacology. Pharmacol Rev 1991; 43: 109-142.

36. Nathan C, Xie Q-W. Nitric oxide synthase: roles, tolls, and controls. Cell 1994; 78: 915-918.

37. Yates DH, Kharitonov SA, Worsdell M, Thomas PS, Barnes PJ. Exhaled nitric oxide is decreased after inhalation of a specific inhibitor of inducible nitric oxide synthase in asthmatic but not in normal subjects. $A m J$ Respir Crit Care Med 1996; 154: 247-250.

38. Nelson BV, Sear S, Woods J, et al. Expired nitric oxide as a marker for childhood asthma. J Pediatr 1997; 130: 423427.

39. Yates DH, Kharitonov SA, Robbins RA, Thomas PS, Barnes PJ. Effects of nitric oxide synthase inhibitor and glucocorticosteroid on exhaled nitric oxide. Am J Respir Crit Care Med 1995; 152: 892-896.

40. Scheding U, Frostell C, Persson MG, Jacobsson J, Andersson G, Gustafsson LE. Contribution from upper and 
lower airways to exhaled endogenous nitric oxide in humans. Acta Anaesth Scand 1995; 39: 327-332.

41. Kimberly B, Nejadnik B, Giraud CD, Holden WE. Nasal contribution to exhaled nitric oxide at rest and during breathholding in humans. Am J Respir Crit Care Med 1996; 153: 829-836.

42. Gerlach H, Rossaint R, Pappert D, Knorr M, Falke KJ. Autoinhalation of nitric oxide after endogenous synthesis in nasopharynx. Lancet 1994; 343: 518-519.

43. Yates DH, Kharitonov SA, Barnes PJ. Effect of short- and long-acting $\beta_{2}$-agonists on exhaled nitric oxide in asthmatic patients. Eur Respir J 1997; 10: 1483-1488.
44. Dotsch J, Demirakça S, Terbrack HG, Huls G, Rascher G, Kuhl PG. Airway nitric oxide in asthmatic children and patients with cystic fibrosis. Eur Respir J 1996; 9: 2537 2540.

45. Frangova Youroukova Y, Silvestri M, Fregonese B, Spallarossa D, Gianiorio P, Rossi GA. Orally exhaled nitric oxide (NO) levels appear to be related to the degree of airway obstruction in untreated childhood asthma. Am J Respir Crit Care Med 1998; 157: A469 (Abstract).

46. Artlich A, Hagenah JU, Jonas S, Ahrens P, Gortner L. Exhaled nitric oxide in childhood asthma. Eur J Pediatr 1996; 155: 689-701. 